\title{
Planar Light Extinction Measurement of Soot Volume Fraction in Laminar Counterflow Diffusion Flames
}

\author{
Jiwei Zhou ${ }^{1,2}$, Mengxiang Zhou ${ }^{1,2}$, Liuhao $\mathrm{Ma}^{1,2 *}$ and Yu Wang ${ }^{1,2 *}$ \\ ${ }^{1}$ Laboratory for Advanced Combustion, School of Automotive Engineering, Wuhan University of Technology, Wuhan, China, \\ ${ }^{2}$ Hubei Key Laboratory of Advanced Technology for Automotive Components and Hubei Collaborative Innovation Center for \\ Automotive Components Technology, Wuhan, China
}

OPEN ACCESS

Edited by:

Chiara Saggese,

United States Department of Energy

(DOE), United States

Reviewed by:

Hu Wang,

Tianjin University, China

Xin Xue,

Beihang University, China

*Correspondence:

Liuhao Ma

liuhaoma@whut.edu.cn

Yu Wang

yu.wang@whut.edu.cn

Specialty section:

This article was submitted to

Engine and Automotive Engineering,

a section of the journal

Frontiers in Mechanical Engineering

Received: 05 June 2021

Accepted: 28 July 2021

Published: 23 August 2021

Citation:

Zhou J, Zhou M, Ma L and Wang $Y$

(2021) Planar Light Extinction

Measurement of Soot Volume Fraction

in Laminar Counterflow

Diffusion Flames.

Front. Mech. Eng 7:720917.

doi: 10.3389/fmech.2021.720917
A cost-effective and straightforward light extinction method has been extensively used for measurement of soot volume fraction (SVF) in sooting flames. The traditional pointwise measurement with translation stage suffers from relatively time-consuming operation and low spatial resolution. In the current study, the planar light extinction method is processed by utilizing a CMOS camera to image the combustion field of counterflow diffusion flame (CDF) backlit with the lamp. Collimated and diffuse optical layouts were adopted to explore the feasibility. Investigations of beam-steering effects are presented and discussed through a combination of computational fluid dynamics (CFD) and ray tracing simulations. Measured SVF are compared to the well-validated laser-induced incandescence (LII) measurements. Current measurements show that the diffuse optical layout is feasible and robust to provide accurate and more efficient measurement of the SVF in CDF with superior spatial resolution $(21.65 \mu \mathrm{m})$.

Keywords: planar light extinction, soot volume fraction, counterflow diffusion flame, ray tracing, beam steering

\section{INTRODUCTION}

Accurate knowledge of soot formation is crucial to many research fields such as energy conversion, carbon emission reduction, combustion, and propulsion (Wang and Chung, 2019). Since the prehistoric times, soot particles have been widely used to manufacture pigments for cave wall painting and ink for writing (Wang, 2011). Nowadays, many daily necessities such as dyes, tires, fertilizers, and plastics are manufactured from soot. On the other hand, soot is one of the major air pollutants produced from the incomplete combustion of fossil fuels, which not only influences the energy utilization efficiency but also becomes a severe threat to human health (Hansen and Nazarenko, 2004; Mukherjee and Agrawal, 2018). Based on previous knowledge (Wang et al., 2013; Yan et al., 2019a), soot formation process mainly involves fuel pyrolysis, aromatic hydrocarbons formation, nucleation, surface grow, particle coagulation, aggregation, and oxidation. The complicated fluid and particles transport, chemical reactions, and heat transfer processes introduce extreme difficulties in accurate kinetic modeling and computational fluid dynamics (CFD) simulations of a complex soot formation process. However, experimental studies of well-controlled laminar flame using advanced diagnostic techniques provide the opportunity for reliable soot formation study with high level of confidence.

Laminar counterflow diffusion flame $(\mathrm{CDF})$ is one of the most representative laminar flames with quasispatial uniformity and temporal stability under controllable boundary conditions (Wang and Chung, 2019). Its significant advantage of fuel flexibility and operation versatility makes it a popular flame for 
combustion chemistry study. Additionally, CDF under a mere soot formation process can be realized at a unique condition. Hence, CDF has attracted more attention for soot formation study over the past several decades. In CDF, accurate measurement of physicochemical parameters related to soot formation with high fidelity is of great significance. Among them, the soot volume fraction (SVF) is a crucial parameter with first priority.

SVF is commonly measured using optical methods, including the light extinction (LE) method (Yan et al., 2019b), laser-induced incandescence (LII) (Sarnacki and Chelliah, 2018), and soot spectral emission (SSE) (Kholghy et al., 2017). LII utilizes the decay radiation signal of soot particles being heated up to $\sim 4,000 \mathrm{~K}$ by a high-energy laser pulse to infer the SVF. SSE measured the SVF by fitting the collected spectral emission of hot soot particles. However, LII usually requires an expensive and bulky laser source while SSE requires frequent calibration of detectors (e.g., PMT and CCD camera) and has relatively low signal-to-noise ratio (SNR) within the visible spectrum in the low-temperature zone of flame. LE used the attenuation of incident light to obtain the SVF. The optical configuration is usually simple and straightforward. The light source such as a laser, LED, or lamp is cheap and commercially available. Till now, such a method has been widely used for SVF measurement from lab-scale flames to practical combustion and propulsion systems (Wei et al., 2019; Eckart et al., 2021).

Typically, path-averaged SVF results were obtained due to the lineof-sight (LOS) nature. To achieve spatially resolved measurements, tomographic reconstruction is usually used based on multidirectional LOS measurements. Taking the widely used laser-based LE method for example, the laser beam was scanned parallel from the center flame to flame edge during the experiment. However, this method is time consuming and usually requires mobility of the burner setup. Therefore, it may not apply to unsteady flames. In addition, the effective spatial resolution depends on the diameter of the laser beam and scan interval. Such a measurement strategy is pointwise measurement and has several hundred micrometers $(\mu \mathrm{m})$ resolution. However, in the presence of CDF with small dimension (8 mm level), the optical measurements with high spatial resolution are desired (Ballester and García-Armingol, 2010). By a combination of an incoherent lamp and camera, planar measurement with superior resolution $(20-50 \mu \mathrm{m})$ is possible. With such optical arrangement, the complexity of the experimental setup is further reduced without the translation stage. Furthermore, it is very convenient to record the transmitted intensity images using the planar laser extinction. Therefore, the efficiency of planar measurement is greatly improved and the measurement for unsteady flame is possible.

However, the CDF has more significant thermochemical gradients in axial direction compared to premixed and coflow flame (Gleason et al., 2018; Zhou et al., 2021). Such a difference will lead to extreme difficulty in optical measurements. For the pointwise laser extinction, the transmitted beam could be successfully directed to the photodetector by using a convex lens and integrating sphere. Nevertheless, the emitted light from the lamp is planar, which introduces significant difficulty in refocusing all the transmitted beams to the active area of the camera. Hence, the key challenge in the application of the planar extinction method is to avoid the beam steering effects caused by flame thermochemical gradients.

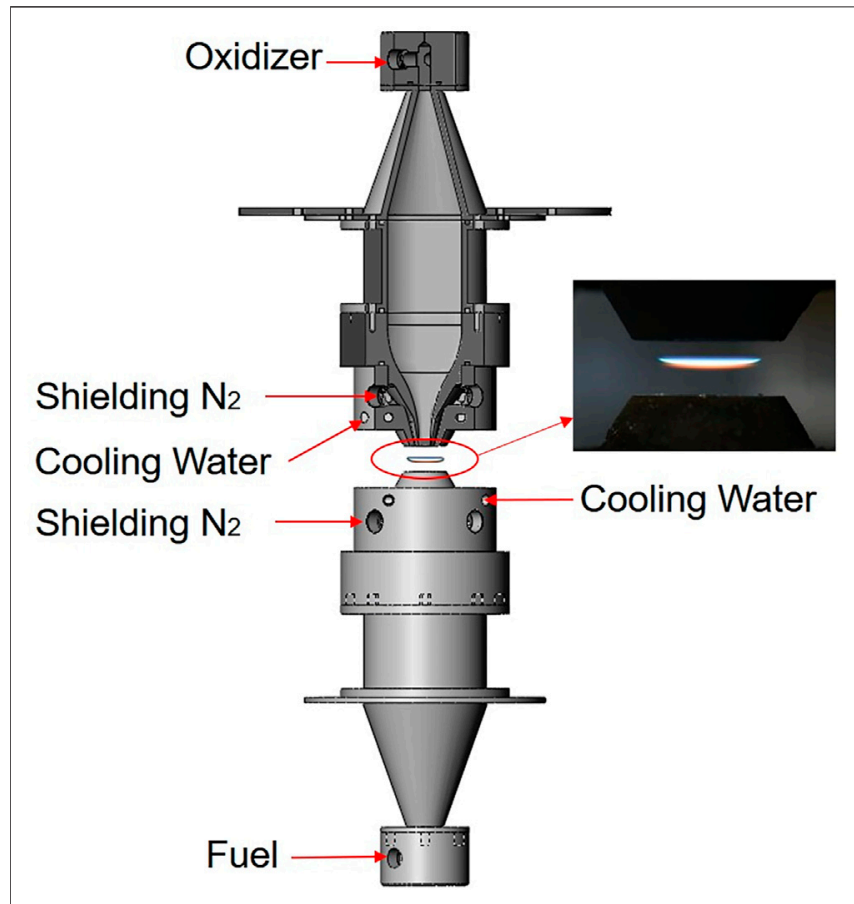

FIGURE 1 | Schematic of the counterflow diffusion flame (CDF) burner.

At present, planar extinction measurement is mainly applied into axisymmetric flame for soot volume fraction. Two layouts of the planar light extinction method are normally used, including collimated and diffuse arrangement (Xin and Gore, 2005; Xu and Lee, 2006; Du et al., 2018). Such two layouts have been previously applied to laminar coflow diffusion flame measurements and appear to have similar performance. In addition, extremely slight deflection could be observed due to the much lower thermochemical gradient in the vertical direction (Snelling et al., 1999). As mentioned above, the thermochemical distribution along the CDF propagation direction (axial direction) is extremely nonuniform, further contributing to the difficulty in capturing the fine flame structure with the superior spatial resolution. Hence, the beam steering is more likely to occur in counterflow flames due to significant thermochemical gradients. In addition, the diffuse layout is observed to have better performance in the presence of beam steering compared with the collimated layout (Thomson et al., 2008). Amin and Roberts performed the diffuse layout for planar extinction measurement of SVF in CDFs (Amin and Roberts, 2020). However, the collimated layout has not been attempted in counterflow flame. And comparative study of the two layouts' performance is sparse. Therefore, further analysis of the beam steering effect on the planar light beam propagation in the two layouts and the related experimental study are both required.

In this work, we performed measurement of SVF in CDF using the planar light extinction method. The two optical layouts were used and compared, including collimated and diffuse arrangement. The feasibility of the two optical configurations was comprehensively analyzed using a joint computational fluid 


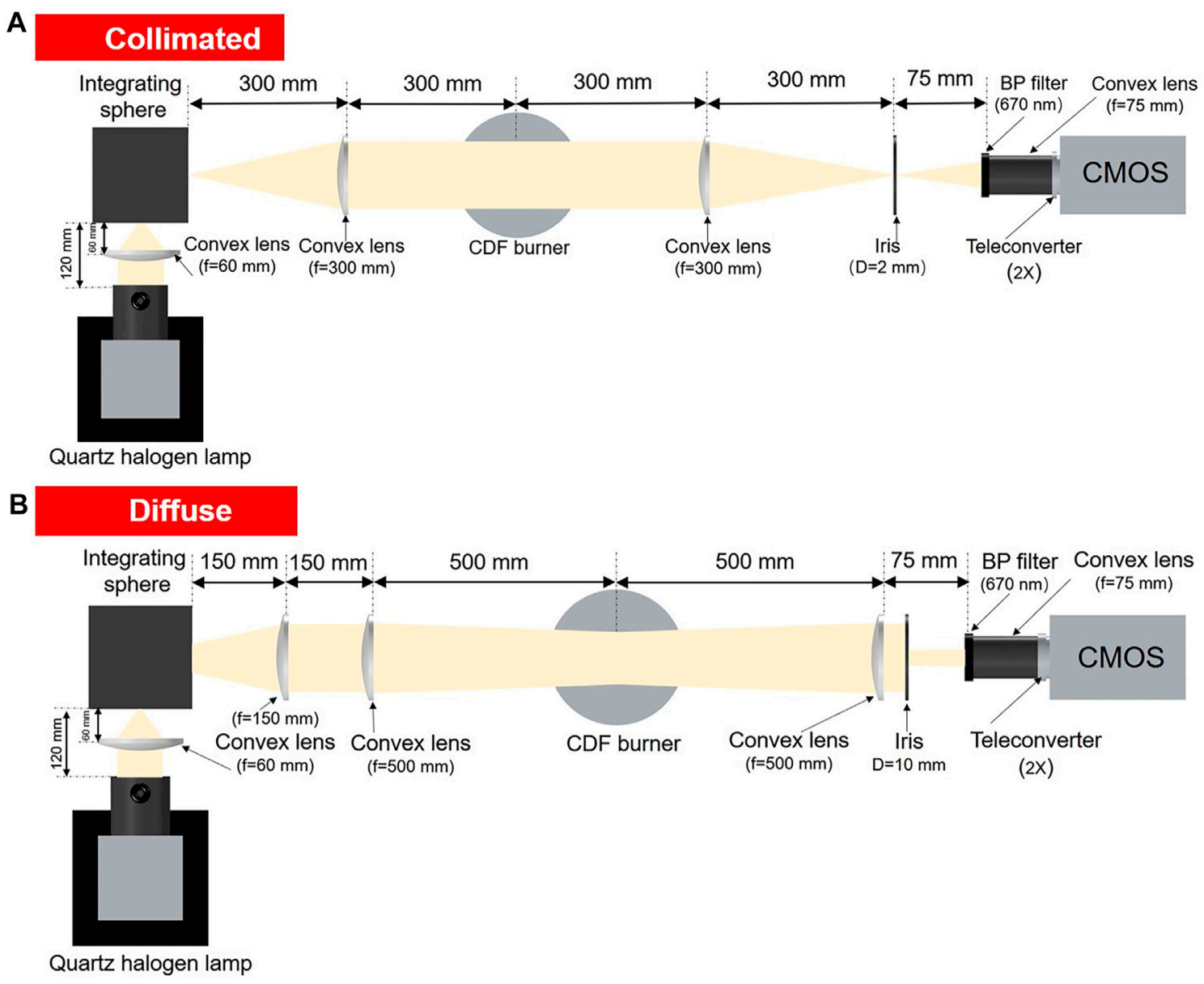

FIGURE 2 | Optical setup with the (A) collimated layout and (B) diffuse layout.

dynamics (CFD) and ray tracing simulation. Comparisons with benchmark LII measurement were also performed to evaluate the performance of the two optical layouts. Further experiments were conducted to verify the diffuse optical layout and explore soot formation at wider CDF conditions.

\section{MEASUREMENT PRINCIPLES}

The light extinction (LE) method exploits the interactions between the incident light and soot particles to determine the soot volume fraction (SVF). The principle of LE is governed by the well-known Beer-Lambert law. When the incident light at optical frequency $v$ travels through the medium with absorbing soot particles and other species, the fractional transmission of incident light can be expressed as

$$
\tau=\frac{I_{t}}{I_{0}}=\exp \left(-\int_{0}^{L} K_{e x t} d l\right)
$$

where $I_{0}$ and $I_{t}$ indicate the incident and transmitted light intensity, respectively; $K_{\text {ext }}\left(\mathrm{cm}^{-1}\right)$ is the extinction coefficient; and $L(\mathrm{~cm})$ represents the total optical path length. The light attenuation is mainly caused by the absorption from soot particles and other molecular/atomic species and scattering from soot particles. Hence, $K_{\text {ext }}$ can be expressed (Simonsson et al., 2015) by the following expression:

$$
K_{\text {ext }}=K_{a b s, \text { soot }}+K_{a b s, \text { otherspecies }}+K_{\text {scat }, \text { soot }},
$$

where $K_{\mathrm{abs}, \text { soot }}$ is the soot particle absorption coefficient, $K_{\mathrm{abs}, \text { otherspecies }}$ is the absorption coefficient induced by other molecular/atomic species, and $K_{\text {scatsoot }}$ represents the soot particle scattering coefficient. According to the Rayleigh-Debye-Gans-polydispersefractal aggregate (RDG-PFA) theory (Koeylue et al., 2002), the soot particle scattering can be neglected when the primary particle size $(D)$ falls in the Rayleigh range, namely, $\pi \mathrm{D} / \lambda<$ 0.3 . For the target counterflow diffusion flame in this work, the average soot particle size is significantly smaller than the wavelength of light. Therefore, the light extinction is solely attributed to the soot absorption once there exists no absorption from other molecules or atoms. Note that the soot extinction coefficient is directly correlated to the particle size distribution function $\mathrm{P}(D)$ such that 


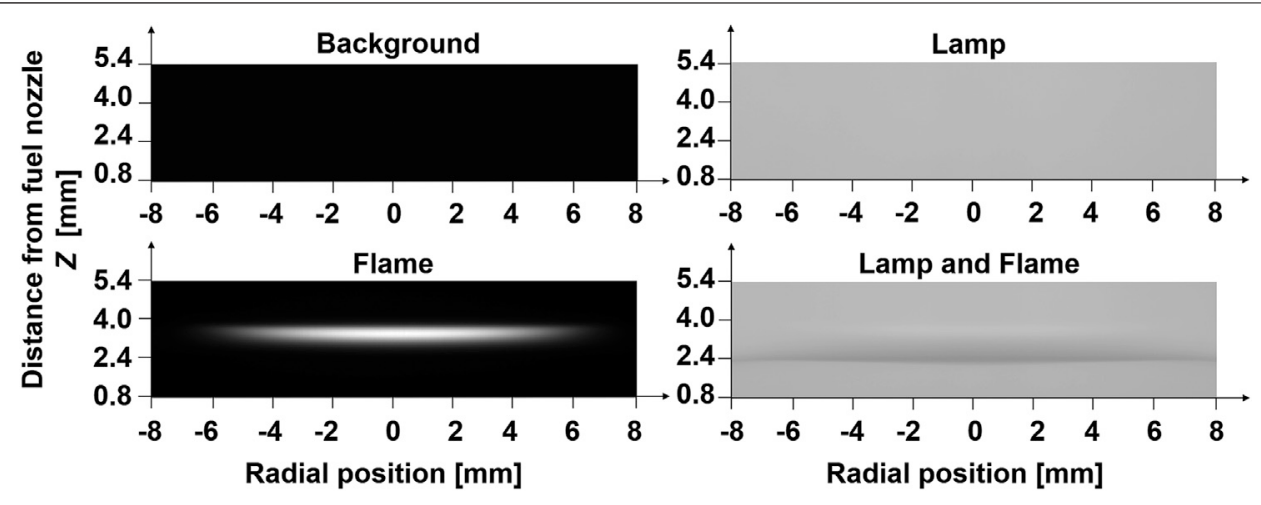

FIGURE 3 | Four types of images corresponding to measurement progress.

$$
K_{\text {ext }}=\frac{\pi^{2}}{\lambda} E(m) N\left|\int_{0}^{\infty} P(D) D^{3}\right| d D
$$

where $D$ and $N$ are the size and total number density of primary particles, respectively. According to the definition, the soot volume fraction (SVF) can be expressed as

$$
S V F=\frac{K_{e x t} \lambda}{6 \pi E(m)}
$$

Both $m$ and $E(m)$ are wavelength-dependent $(\lambda)$ soot optical property parameters. Also, it is discussed in a previous study in counterflow diffusion flames (Yan et al., 2019b). An inversion algorithm (Dasch, 1992; Walsh et al., 2000) can be used to derive local $K_{\text {ext }}$ from parallel measurements. For the purpose of comparing the measured soot volume fraction with the same $E(m)$, the $m$ was assumed as a constant value of $1.57-0.56 i$, and hence, $E(m)$ equals to 0.259 obtained by $E(m)=-\operatorname{Im}\left[\left(m^{2}-1\right) /\left(m^{2}+2\right)\right]$, which is consistent with the previous study (Yan et al., 2019b). It is noted that the value of $m=1.57-0.56 i$ is used widely in diffusion flames (Choi et al., 2011; Wang et al., 2015; Singh et al., 2016) and the value of $m$ did not affect the relative variation of measured SVF with flame conditions.

\section{EXPERIMENT DETAILS}

\section{Burner Configuration}

In this work, measurements were performed on ethylene $\left(\mathrm{C}_{2} \mathrm{H}_{4}\right)$ counterflow diffusion flame (CDF). A schematic of the burner is shown in Figure 1. The burner consists of two identical nozzles with an inner diameter of $10 \mathrm{~mm}$ opposing each other with a separation distance of $8 \mathrm{~mm}$ (Joo et al., 2013). The oxidizer and the fuel were supplied through the upper and the lower nozzles, respectively. To avoid the disturbance of ambient air on the flames, $\mathrm{N}_{2}$ shielding gas was provided through circular slots concentric with the nozzles. Flow rates of fuel, oxidizer, and coflow are controlled by thermalbased mass flow controllers (MFCs). Note that the oxidizer stream was always composed of $\mathrm{O}_{2}$ and $\mathrm{N}_{2}$ ( $X_{\mathrm{O}}$ is defined as the mole fraction of oxygen in the oxidizer stream). The fuel

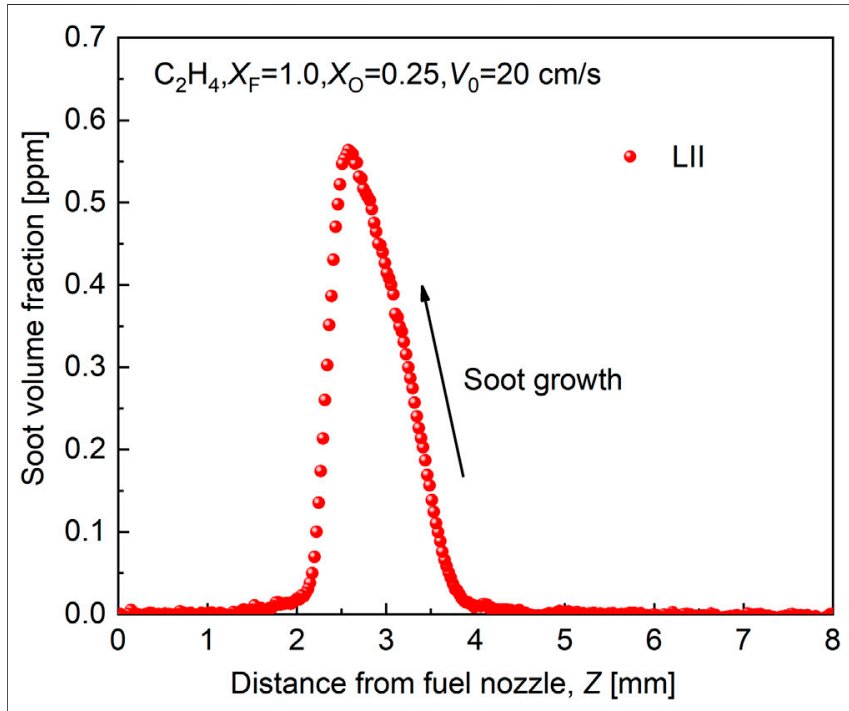

FIGURE 4 | The soot volume fraction profile at the axis measured by calibrated LII.

stream was always the pure ethylene $\left(X_{\mathrm{F}}=1.0\right)$. Also, $V_{0}$ is defined as the nozzle exit average velocity.

\section{Optical Setup}

The optical configuration for spatially resolved light extinction includes one Complementary Metal Oxide Semiconductor (CMOS) camera that records the combustion-field image backlit with the light source. The straightforward arrangement, suitable for the axisymmetric counterflow diffusion flame, involves a quartz halogen lamp (Newport, QTH6333) and a 16 bits scientific monochrome CMOS camera (Andor, Zyla 4.2 plus) with 2048by-2048 pixel. The lamp was precisely controlled by using a lownoise driver (ORIEL, OPS-Q250). The emitted light from the quartz halogen lamp falls into the wavelength range of $200-2,400 \mathrm{~nm}$, and the lamp was operated at the power of $\sim 100 \mathrm{~W}$. For each experiment, a narrow bandpass filter (Thorlabs, FB670-10) was placed in front of the camera to transmit the light near $670 \mathrm{~nm}$. The frame rate is 


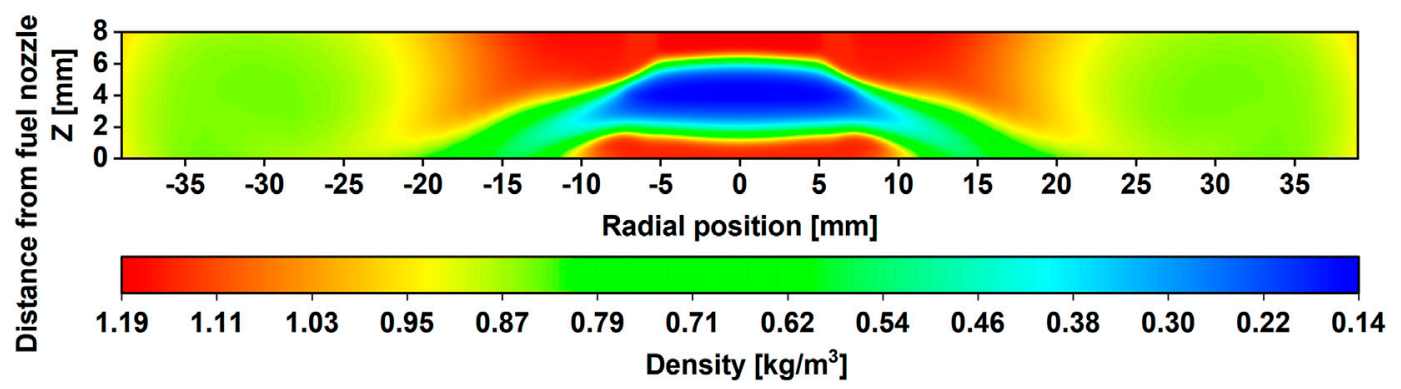

FIGURE 5 | Density contour in counterflow diffusion flame.

$91 \mathrm{~Hz}$ with an exposure time of $90 \mathrm{~ms}$. Before performing the intensive experiments, the lamp and camera were warmed up for 5-10 min to reach the steady operation mode.

As illustrated in Figure 2, two typical optical layouts were used, including the collimated and diffusive arrangements. For the collimated layout, the light emitted from the lamp was focused into the integrating sphere and then diffused at the exit of integrating sphere. Another convex lens directs the light through the flame in a collimated way. When the emitted collimated light was directed through the flame region, the transmitted light was passed through a series of lenses and a teleconverter before entering the active area of the camera.

For the diffuse layout, the diffused light from integrating sphere travels through a pair of convex lenses. The light was then focused on the flame center and then expanded onto another convex lens, which was used to project the flame image onto a CMOS camera using a convex lens. Note that, for both optical layouts, an iris is used to avoid vignetting even in presence of beam steering. The spatial resolution was estimated to be $21.65 \mu \mathrm{m}$.

\section{Measurement Process}

Accurate knowledge of the incident light intensity $I_{0}$ and transmitted intensity $I_{\mathrm{t}}$ is crucial to the measured accuracy and feasibility. Therefore, experiments were performed in a quasidark environment to obtain reliable $I_{0}$ and $I_{\mathrm{t}}$. Firstly, background images were recorded when the halogen lamp was off, and no ignition occurs. The intensity of image is defined as $I_{\mathrm{b}}$. Then, the burner is turned on till the CDF becomes stable. Also, the intensity of the image is recorded with flame $\left(I_{b f}\right)$. Subsequently, the halogen lamp is turned on and the burner is shut down till the record intensity $\left(I_{l}\right)$ becomes stable. Finally, the burner is turned on till the CDF becomes stable again and the intensity of the transmitted image $\left(I_{l f}\right)$ is recorded. The four types of images mentioned above are shown in Figure 3. According to Eq. 1, the transmittance can be described as follows:

$$
\tau=\frac{I_{l f}-I_{b f}}{I_{l}-I_{b}} .
$$

It should be noted that each kind of images should be averaged for 100 times to mitigate the random white noise in the optical

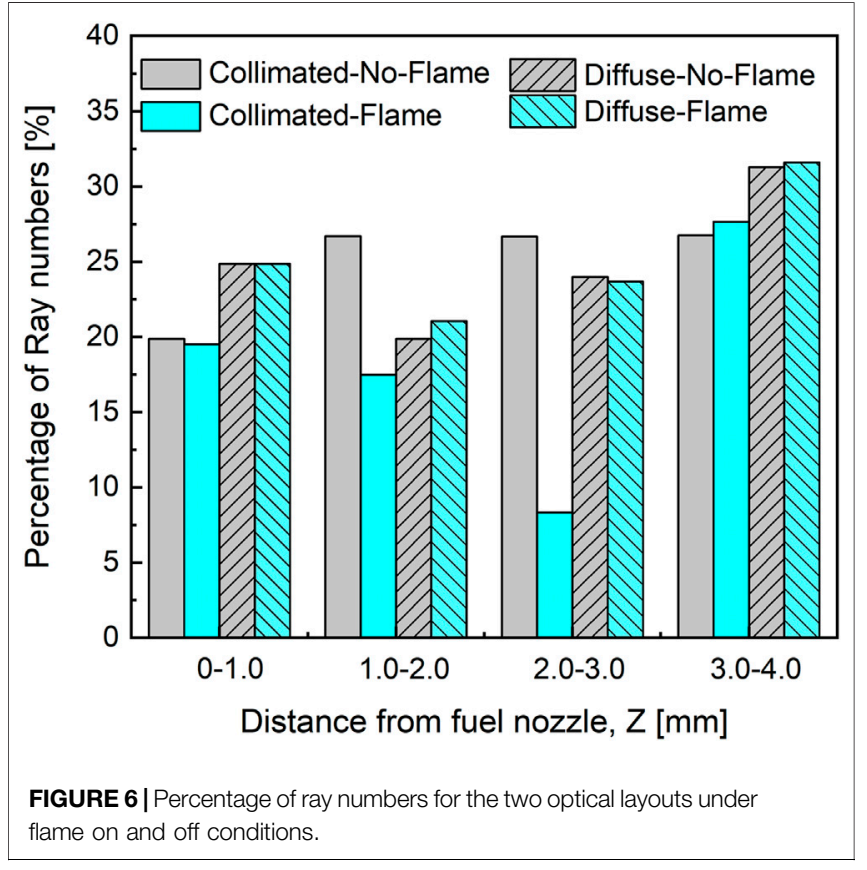

system (i.e., light source and CMOS camera) and improve the signal-to-noise ratio (SNR).

\section{RESULTS AND DISCUSSION}

\section{Feasibility Analysis}

The SVF measurements of CDF with large refractive index gradient caused by evident density gradient field is prone to distortion due to beam steering. For the planar light extinction measurements, the relocation of the transmitted on the target region of the camera is quite challenging. Firstly, we analyze the feasibility of the planar light extinction method for a typical CDF condition $\left(X_{\mathrm{F}}=1.0, X_{\mathrm{O}}=0.25, V_{0}=20 \mathrm{~cm} / \mathrm{s}\right)$ under a collimated and diffuse optical setup. To validate the current measurements, improved LII measurements, which were similar to those in a previous study (Yan et al., 2019a), were also conducted. It should be noted that the LII system is calibrated by pointwise laser extinction measurement and the 


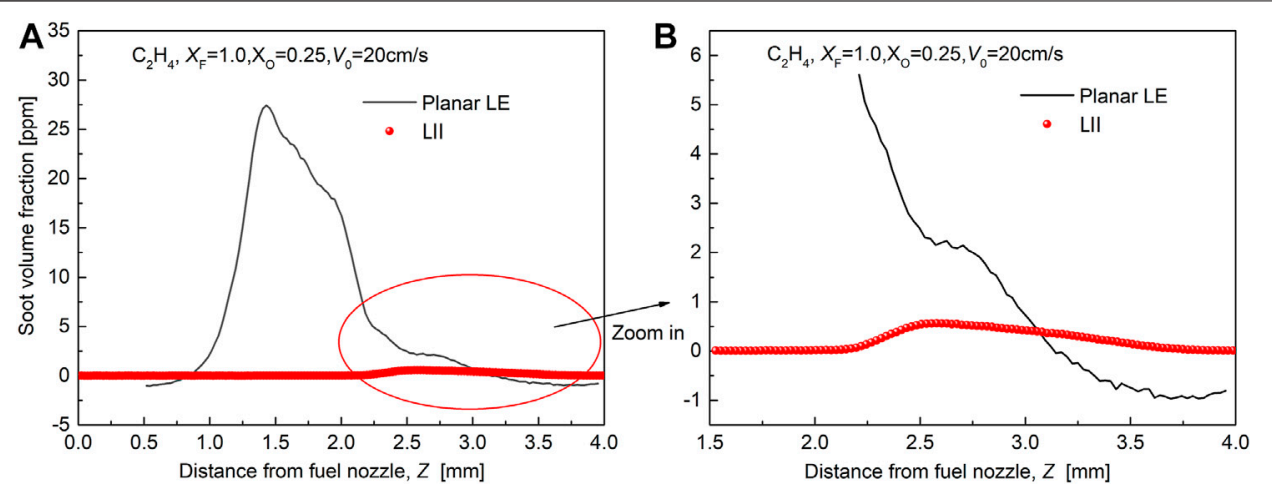

FIGURE 7 | SVF measured by the collimated-light layout: (A) whole flame region; (B) zoom-in area near the oxidizer nozzle.

measurement spatial resolution is $24 \mu \mathrm{m}$. The axial distribution of soot volume fraction (SVF) measured by the calibrated LII method is shown in Figure 4. The soot formation region is observed to locate within $Z=2-4 \mathrm{~mm}$.

To qualitative figure out the beam-steering effect for two different optical setups, numerical studies were performed using a joint simulation of computational fluid dynamics (CFD) and ray tracing. In terms of the ray tracing modeling, the input parameters for two pairs of convex lenses and iris follow the corresponding specifications of detailed optical components. The light source from the integrating sphere exit port is replaced by an equal plane of Lambertian radiance, and a convex lens $(f=150 \mathrm{~mm})$ is used to replace the combination of the convex lens $(f=75 \mathrm{~mm})$ and teleconverter. Therefore, the CMOS image plane is defined at the focal plane of the last convex lens $(f=150 \mathrm{~mm})$. The medium of $\mathrm{CDF}$ is simulated by a cylindrical region with a height of $8 \mathrm{~mm}$ and a radius of $40 \mathrm{~mm}$. The wavelength of the input rays is set as $670 \mathrm{~nm}$, and the bandpass filter is nonexistent in the ray tracing simulation. Opensource CFD solver laminarSMOKE is used to provide the density distribution about the central plane of CDF (Cuoci et al., 2013a; Cuoci et al., 2013b; Cuoci et al., 2015), and three-dimensional interpolation is performed to obtain the density distribution of the whole cylindrical region. Subsequently, the refractive index distribution can be calculated with the Gladstone-Dale formula (Chen et al., 2009) and was then imported for the tracing simulation. The simulations were carried out in the case of the existence and nonexistence of the CDF modeling, respectively. Ray numbers that arrived at the image plane of the camera were counted to perform the subsequent analysis.

Figure 5 presents the density contour of the representative CDF. A significant density gradient is observed within the region of $Z=2-4 \mathrm{~mm}$ close to the fuel nozzle, which is coincident with the soot formation region. The density-gradient-induced beam steering is predicted to occur in this region and has the potential of influencing the planar light extinction measurement. Therefore, accurate and reliable measurements in such a gradient region are significantly challenging.

Figure 6 presents the percentage of the ray numbers arrived at the image plane of the camera along the axial directions for two collimated and diffuse layouts. Owing to the nonsooting region $(Z>$ $4 \mathrm{~mm}$ ), the percentage of the ray numbers arrived at the image plane

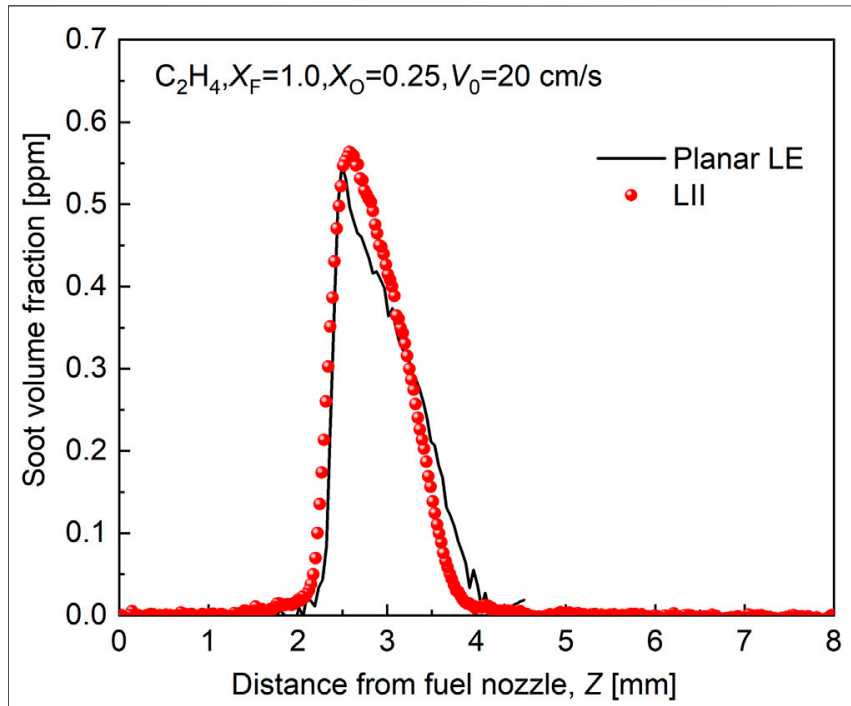

FIGURE 8 | Comparison of LII and planar LE measurement with the diffuse optical setup.

is not presented in Figure 6. Slight discrepancy of ray numbers between flame on and off conditions indicates that the beam steering caused by the flame was not evident. For the collimated layout, the ray numbers decrease significantly and evident beam steering was found within 1.0-3.0 $\mathrm{mm}$ when the flame was on. This is consistent with fact that the evident soot formation occurs in this region of $\mathrm{CDF}$. However, the ray numbers within the region of interest remain constant for the flame on and off condition. Hence, it could be predicted that the diffuse optical setup outperforms the collimated optical setup in the SVF measurements. To further demonstrate our predictions, the experiments were also performed using both collimated and diffuse layout.

Figure 7A compared the axial distribution of SVF measured by planar light extinction with a collimated layout and calibrated LII. There exists a significant difference between the two measurements. More specifically, higher value of SVF was observed in the region of $Z=1-2 \mathrm{~mm}$ where there should be no soot formation (shown in Figure 4). The SVF was 

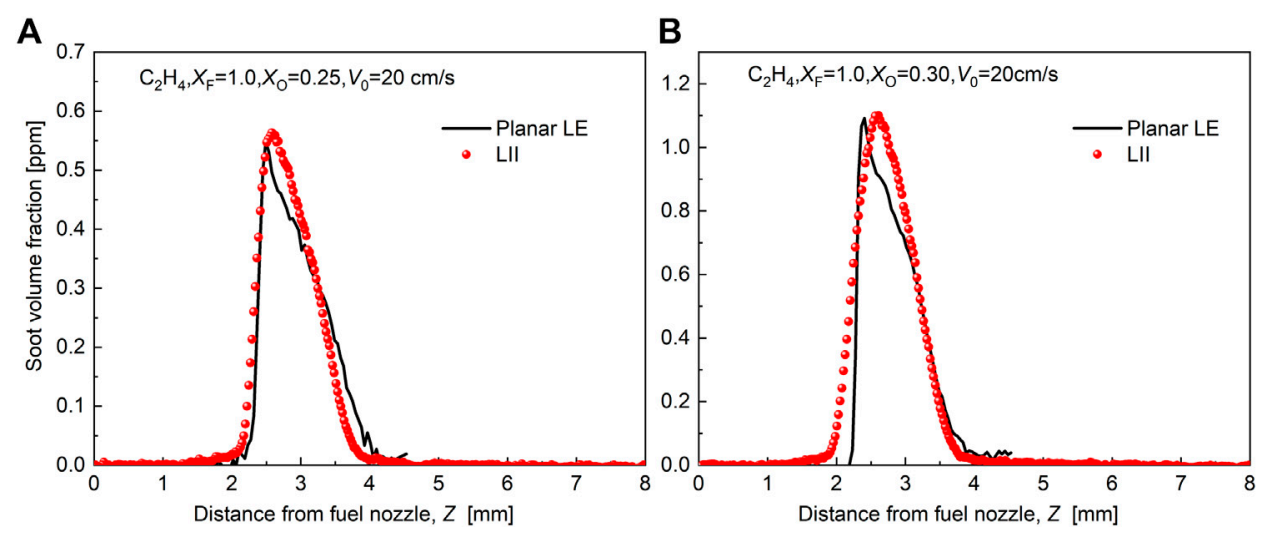

FIGURE 9 | Axial distribution of SVF with various $X_{O}$.

overestimated in the sooting region of $\mathrm{Z}=2-3 \mathrm{~mm}$. It can be explained that the density gradient caused by the soot particle and gaseous species in these regions is extremely evident, contributing to the significant gradient of refractive index. Hence, the beam steering will cause the strong attenuation of light intensity, leading to the dramatical increase of SVF and sharp axial profile. As illustrated in Figure $\mathbf{7 B}$, the measured SVF is negative within the region above $3.0 \mathrm{~mm}$. This may be because the camera detected the ray from other locations affected by beam steering to increase the intensity of light.

However, such a beam-steering effect is negligible for the diffuse layout. Figure 8 compares the measured SVF by diffuse light extinction and LII. The planar measurements well capture the magnitude and position of SVF and the axial distribution of SVF with the measurement result of calibrated LII. The peak SVF is $\sim 0.56 \mathrm{ppm}$ and locates at $Z=\sim 2.5 \mathrm{~mm}$ distance from the fuel nozzle. Although there exists possible beam steering in the soot formation region, the good agreement with LII measurements indicates that such a beam-steering effect is suppressed in the diffuse optical setup. Note that slight discrepancy is still observed between the two methods. It is possible to be caused by the different uncertainty of spatial resolution during the calibration process of planar laser extinction and LII. The numerical errors and algorithms of tomographic reconstruction may also lead to such slight difference.

\section{Multiflame Condition Verification}

Based on the aforementioned findings, the diffuse optical setup is more suitable for measurement of soot volume fraction in CDF. To further demonstrate the stability and feasibility of the current method, applications to a series of representative CDF conditions were performed and comparisons were made to the calibrated LII measurements. When the nozzle exit average velocity $\left(V_{0}=20 \mathrm{~cm} / \mathrm{s}\right)$ and the mole fraction of fuel in fuel stream $\left(X_{\mathrm{F}}=\right.$ 1.0 ) were fixed, the SVFs were measured in the CDF with different $X_{\mathrm{O}}$. Figure 9 shows that the SVF increases with increasing $X_{\mathrm{O}}$ and the position of peak SVF appears at $Z=\sim 2.5 \mathrm{~mm}$. This is because the increasing temperature induced by the oxidized enhanced the pyrolysis of fuel and soot growth, contributing to the more evident

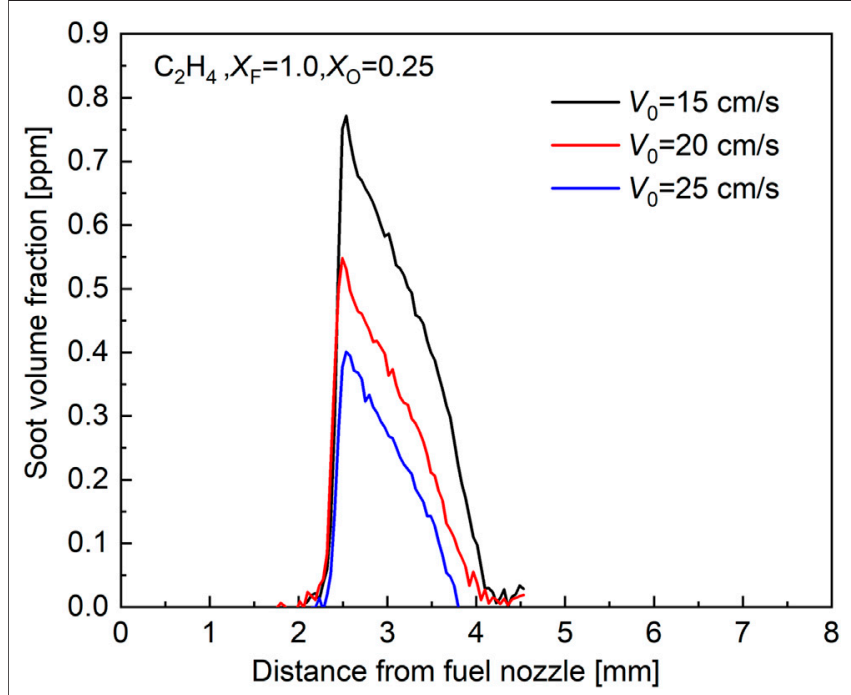

FIGURE 10 | Axial distribution of SVF at various $V_{0}$ of fuel and oxidizer stream.

soot formation. In terms of the axial distribution of soot volume fraction, the planar light extinction measurements were in good agreement with the well-validated calibrated LII measurements.

The sooting characteristics are sensitive to the flow residence time due to the dependence of soot formation and growth on kinetics (Du et al., 1989). The flow residence time owing is inversely proportional to flow strain rate in CDF. A variation of the nozzle exit velocity systematically alters the strain rate of CDFs. Figure $\mathbf{1 0}$ depicts the measurements at a fixed mole fraction of fuel in the fuel stream $\left(X_{\mathrm{F}}=1.0\right)$ and oxygen in the oxidizer stream $\left(X_{\mathrm{O}}=0.25\right)$ with different nozzle exit average velocities (i.e., strain rate, $V_{0}=$ $15-25 \mathrm{~cm} / \mathrm{s}$ ). The SVF decreases gradually with the increase of $V_{0}$. Increased $V_{0}$ accelerates the flow speed of gas species in the soot formation region, contributing the less time for nucleation, surface growth, coagulation, and aggregation. The abovementioned measurements further demonstrate the accuracy and feasibility of the current planar light extinction measurements. 


\section{CONCLUSION}

In this work, quantitative measurement of soot volume fraction in counterflow diffusion flame (CDF) was realized using the planar light extinction method. Typical collimated and diffuse optical layouts were set up. Joint computational fluid dynamics (CFD) and ray tracing simulations were performed to analyze the discrepancy between two layouts caused by the unwanted beam-steering effect. The planar LE measurement results using two layouts were compared with LII measurements. Finally, more measurements were conducted for various flame conditions to further validate the current method. The following major conclusions were drawn:

1) The collimated optical layout is not suitable for SVF measurements in CDF. Within the soot formation region, the excessive SVF is measured due to strong beam-steering effect.

2) The diffuse optical layout is demonstrated against the various $\mathrm{CDF}$ conditions and has the advantages of suppressing the beam-steering effect.

3) The planar light extinction method with a diffuse optical layout is effective and robust for SVF measurements with superior spatial resolution compared to the previous pointwise laser extinction method.

\section{REFERENCES}

Amin, H. M. F., and Roberts, W. L. (2020). Investigating soot parameters in an ethane/air counterflow diffusion flame at elevated pressures. Combust. Sci. Technol. 193, 1827-1842. doi:10.1080/00102202.2020.1715964

Ballester, J., and García-Armingol, T. (2010). Diagnostic Techniques for the Monitoring and Control of Practical Flames. Prog. Energ. Combustion Sci. 36, 375-411. doi:10.1016/j.pecs.2009.11.005

Chen, Y., Li, Z., Song, Y., and He, A. (2009). Extension of the Gladstone-Dale Equation for Flame Flow Field Diagnosis by Optical Computerized Tomography. Appl. Opt. 48, 2485-2490. doi:10.1364/ao.48.002485

Choi, B. C., Choi, S. K., Chung, S. H., Kim, J. S., and Choi, J. H. (2011). Experimental and Numerical Investigation of Fuel Mixing Effects on Soot Structures in Counterflow Diffusion Flames. Int.J Automot. Technol. 12, 183-191. doi:10.1007/s12239-011-0022-Z

Cuoci, A., Frassoldati, A., Faravelli, T., and Ranzi, E. (2013a). A Computational Tool for the Detailed Kinetic Modeling of Laminar Flames: Application to C2H4/CH4 Coflow Flames. Combustion and Flame 160, 870-886. doi:10.1016/ j.combustflame.2013.01.011

Cuoci, A., Frassoldati, A., Faravelli, T., and Ranzi, E. (2013b). Numerical Modeling of Laminar Flames with Detailed Kinetics Based on the Operator-Splitting Method. Energy Fuels 27, 7730-7753. doi:10.1021/ef4016334

Cuoci, A., Frassoldati, A., Faravelli, T., and Ranzi, E. (2015). OpenSMOKE++: An Object-Oriented Framework for the Numerical Modeling of Reactive Systems with Detailed Kinetic Mechanisms. Computer Phys. Commun. 192, 237-264. doi:10.1016/j.cpc.2015.02.014

Dasch, C. J. (1992). One-dimensional Tomography: a Comparison of Abel, OnionPeeling, and Filtered Backprojection Methods. Appl. Opt. 31, 1146-1152. doi:10.1364/AO.31.001146

Du, C., Andersson, S., and Andersson, M. (2018). Two-dimensional Measurements of Soot in a Turbulent Diffusion Diesel Flame: the Effects of Injection Pressure, Nozzle Orifice Diameter, and Gas Density. Combustion Sci. Technology 190, 1659-1688. doi:10.1080/00102202.2018.1461850

Du, D. X., Axelbaum, R. L., and Law, C. K. (1989). Experiments on the Sooting Limits of Aerodynamically-Strained Diffusion Flames. Symp. (International) Combustion 22, 387-394. doi:10.1016/s0082-0784(89)80045-1

\section{DATA AVAILABILITY STATEMENT}

The original contributions presented in the study are included in the article/supplementary material; further inquiries can be directed to the corresponding authors.

\section{AUTHOR CONTRIBUTIONS}

JZ: investigation, formal analysis, visualization, and writing-original draft preparation. MZ: formal analysis and writing-review and editing. LM: methodology, formal analysis, writing-review and editing, and supervision. YW: conceptualization, methodology, formal analysis, writing-review and editing, and supervision.

\section{FUNDING}

This work was supported by the National Natural Science Foundation of China (51976142), Fundamental Research Funds for the Central Universities (WUT:2021IVA016), and Startup Funding of Wuhan University of Technology (40120607).

Eckart, S., Yu, C., Maas, U., and Krause, H. (2021). Experimental and Numerical Investigations on Extinction Strain Rates in Non-premixed Counterflow Methane and Propane Flames in an Oxygen Reduced Environment. Fuel 298, 120781. doi:10.1016/j.fuel.2021.120781

Gleason, K., Carbone, F., and Gomez, A. (2018). Effect of Temperature on Soot Inception in Highly Controlled Counterflow Ethylene Diffusion Flames. Combustion and Flame 192, 283-294. doi:10.1016/j.combustflame.2018.02.001

Hansen, J., and Nazarenko, L. (2004). Soot Climate Forcing via Snow and Ice Albedos. Proc. Natl. Acad. Sci. 101, 423-428. doi:10.1073/pnas.2237157100

Joo, P. H., Wang, Y., Raj, A., and Chung, S. H. (2013). Sooting Limit in Counterflow Diffusion Flames of Ethylene/propane Fuels and Implication to Threshold Soot index. Proc. Combustion Inst. 34, 1803-1809. doi:10.1016/j.proci.2012.06.124

Kholghy, M. R., Afarin, Y., Sediako, A. D., Barba, J., Lapuerta, M., Chu, C., et al. (2017). Comparison of Multiple Diagnostic Techniques to Study Soot Formation and Morphology in a Diffusion Flame. Combustion and Flame 176, 567-583. doi:10.1016/j.combustflame.2016.11.012

Koeylue, U., Xing, Y., Rosner, D. E, Bengtsson, P.-E., and Bladh, H. (2002). Fractal morphology analysis of combustion-generated aggregates using angular light scattering and electron microscope images. Langmuir 11, 4848-4854. doi:10.1021/la00012a043

Mukherjee, A., and Agrawal, M. (2017). A Global Perspective of Fine Particulate Matter Pollution and its Health Effects. Rev. Environ. Contam. Toxicol. 244, 5-51. doi:10.1007/398_2017_3

Sarnacki, B. G., and Chelliah, H. K. (2018). Sooting Limits of Non-premixed Counterflow Ethylene/oxygen/inert Flames Using LII: Effects of Flow Strain Rate and Pressure (Up to 30 Atm). Combustion and Flame 195, 267-281. doi:10.1016/j.combustflame.2018.03.029

Simonsson, J., Olofsson, N.-E., Török, S., Bengtsson, P.-E., and Bladh, H. (2015). Wavelength dependence of extinction in sooting flat premixed flames in the visible and near-infrared regimes. Appl. Phys. B 119, 657-667. doi:10.1007/ s00340-015-6079-Z

Singh, P., Hui, X., and Sung, C.-J. (2016). Soot Formation in Non-premixed Counterflow Flames of Butane and Butanol Isomers. Combustion and Flame 164, 167-182. doi:10.1016/j.combustflame.2015.11.015

Snelling, D. R., Thomson, K. A., Smallwood, G. J., and Gülder, Ö. L. (1999). Twodimensional Imaging of Soot Volume Fraction in Laminar Diffusion Flames. Appl. Opt. 38, 2478-2485. doi:10.1364/ao.38.002478 
Thomson, K. A., Johnson, M. R., Snelling, D. R., and Smallwood, G. J. (2008). Diffuse-light Two-Dimensional Line-Of-Sight Attenuation for Soot Concentration Measurements. Appl. Opt. 47, 694-703. doi:10.1364/ao.47.000694

Walsh, K. T., Fielding, J., and Long, M. B. (2000). Effect of Light-Collection Geometry on Reconstruction Errors in Abel Inversions. Opt. Lett. 25, 457-459. doi:10.1364/ol.25.000457

Wang, H. (2011). Formation of Nascent Soot and Other Condensed-phase Materials in Flames. Proc. Combustion Inst. 33, 41-67. doi:10.1016/ j.proci.2010.09.009

Wang, Y., and Chung, S. H. (2019). Soot Formation in Laminar Counterflow Flames. Prog. Energ. Combustion Sci. 74, 152-238. doi:10.1016/j.pecs.2019.05.003

Wang, Y., Raj, A., and Chung, S. H. (2013). A PAH Growth Mechanism and Synergistic Effect on PAH Formation in Counterflow Diffusion Flames. Combustion and Flame 160, 1667-1676. doi:10.1016/j.combustflame.2013.03.013

Wang, Y., Raj, A., and Chung, S. H. (2015). Soot Modeling of Counterflow Diffusion Flames of Ethylene-Based Binary Mixture Fuels. Combustion and Flame 162, 586-596. doi:10.1016/j.combustflame.2014.08.016

Wei, S., Zhao, X., Xu, R., and He, C. (2019). The Measurement of SVF of Ethanol Gasoline Based on Two-Dimensional Light Extinction Method. Energy Sourc. A: Recovery, Utilization, Environ. Effects, 1-13. doi:10.1080/ 15567036.2019.1649327

Xin, Y., and Gore, J. P. (2005). Two-dimensional Soot Distributions in Buoyant Turbulent Fires. Proc. Combustion Inst. 30, 719-726. doi:10.1016/ j.proci.2004.08.126

Xu, Y., and Lee, C.-f. F. (2006). Forward-illumination Light-Extinction Technique for Soot Measurement. Appl. Opt. 45, 2046-2057. doi:10.1364/ao.45.002046

Yan, F., Xu, L., Wang, Y., Park, S., Sarathy, S. M., and Chung, S. H. (2019a). On the Opposing Effects of Methanol and Ethanol Addition on PAH and Soot
Formation in Ethylene Counterflow Diffusion Flames. Combustion and Flame 202, 228-242. doi:10.1016/j.combustflame.2019.01.020

Yan, F., Zhou, M., Xu, L., Wang, Y., and Chung, S. H. (2019b). An Experimental Study on the Spectral Dependence of Light Extinction in Sooting Ethylene Counterflow Diffusion Flames. Exp. Therm. Fluid Sci. 100, 259-270. doi:10.1016/j.expthermflusci.2018.09.008

Zhou, M., Yan, F., Zhong, X., Xu, L., and Wang, Y. (2021). Sooting Characteristics of Partially-Premixed Flames of Ethanol and Ethylene Mixtures: Unravelling the Opposing Effects of Ethanol Addition on Soot Formation in Non-premixed and Premixed Flames. Fuel 291, 120089. doi:10.1016/j.fuel.2020.120089

Conflict of Interest: The authors declare that the research was conducted in the absence of any commercial or financial relationships that could be construed as a potential conflict of interest.

Publisher's Note: All claims expressed in this article are solely those of the authors and do not necessarily represent those of their affiliated organizations or those of the publisher, the editors, and the reviewers. Any product that may be evaluated in this article, or claim that may be made by its manufacturer, is not guaranteed or endorsed by the publisher.

Copyright (c) 2021 Zhou, Zhou, Ma and Wang. This is an open-access article distributed under the terms of the Creative Commons Attribution License (CC BY). The use, distribution or reproduction in other forums is permitted, provided the original author(s) and the copyright owner(s) are credited and that the original publication in this journal is cited, in accordance with accepted academic practice. No use, distribution or reproduction is permitted which does not comply with these terms. 